\title{
ON INTUTIONISTIC FUZZY SUPRA PRE-OPEN SET AND INTUTIONISTIC FUZZY SUPRA-P RE-CONTINUITY ON TOPOLOGICAL SPACES
}

\author{
C. Indirani $^{1}$
}

Abstract- In this paper, we introduce and investigate a new class of sets and functions between topological spaces called intuitionostic fuzzy supra pre-open set intuitionistic fuzzy supra pre-continious functions and intuitionistic fuzzy supra pre- open maps respectively.

Keywords -Intuitionistic fuzzy supra topological spaces, intuitionistic fuzzy supra preopen sets, intuitionistic fuzzy supra pre-continuous mappings and intuitionistic fuzzy supra pre-open set.

\section{Introduction and preliminaries}

The concept of intuitionistic fuzzy set is defined by Atanassov as a general- ization of the concept of fuzzy set given by Zadeh [13]. Using the notation of intuitionistic fuzzy sets, Coker [3] introduced the notation of intuitionistic fuzzy topological spaces. In 1983 Mashhour et al [8] inrtoduced the supra topological spaces and studied s-continuous maps and $s^{\square}$ - continuous functions. In 1987, Abd El-Monsef et al. [1] introduced the supra topological spaces and studied fuzzy supra-continuous functions and obtained some properties and characteriza- tions. In 1996, Won Keun Min [12] introduced fuzzy scontinuous, fuzzy s-open and fuzzy s-closed maps and established a number of characterizations. In 2008, Devi et al [4] introduced and studied a class of sets and a maps between topo- logical spaces called supra $\alpha$-open and supra $\alpha$-continuous functions and studied some of the basic properties for this class of functions. In 1999, Necla Turanl [11] introduced the concept of intuitionistic fuzzy supra topological space. In this pa- per, we study the basic properties of intuitionistic fuzzy supra pre-open sets and introduce the notation of intuitionistic fuzzy supra pre-continuous maps and investigate several properties of intuitionistic fuzzy supra pre-continuous maps.

Throughout this paper, by $(X, \tau)$ or simply by $X$ we will denote the intuitionistic fuzzy supra topological space (briefly, IFsTS). For a subset A of a space $(X, \tau), \operatorname{cl}(A)$, $\operatorname{int}(\mathrm{A})$ and $\overline{\mathrm{A}}$ denote the closure of $\mathrm{A}$, the interior of $\mathrm{A}$ and the complement of $\mathrm{A}$ respectively. Each intuitionistic fuzzy supra set (briefly, IFsS) which belongs to $(X, \tau)$ is

\footnotetext{
${ }^{1}$ Bannari Amman Institute Of Technology, Sathyamangalam 638401.
} 
called intuitionistic fuzzy supra open set (briefly, IF-sOS) in X. The complement of an IFsOS $A$ in $X$ is called an intuitionistic fuzzy supra fuzzy supra closed set (IFsCS) in $X$. We introduce some basic notations and results that are used in the sequel.

Definition 1.1. [2] Let $\mathrm{X}$ be a non empty fixed set and $\mathrm{I}$ be the closed interval $[0,1]$. An intuitionistic fuzzy set (IFS) $\mathrm{A}$ is an object of the following form

$$
\mathrm{A}=\left\{<\mathrm{x}, \mu_{\mathrm{A}}(\mathrm{x}), v_{\mathrm{A}}(\mathrm{x})>: \mathrm{x} \square \mathrm{X}\right\} .
$$

where the mappings $\mu_{\mathrm{A}}: \mathrm{X} \rightarrow \mathrm{I}$ and $v_{\mathrm{A}}: \mathrm{X} \rightarrow \mathrm{I}$ denote the degree of membership (namely $v_{A}(x)$ ) and the degree of nonmembership (namely $\mu_{A}(x)$ ) for each element $x \square X$ to the set A respectively and $0 \leq \mu_{A}(\mathrm{x})+v_{A}(\mathrm{x}) \leq 1$ for each $\mathrm{x} \square \mathrm{X}$. Obviously, every fuzzy set $\mathrm{A}$ on a nonempty set $\mathrm{X}$ is an IFS of the following form

$$
\mathrm{A}=\left\{<\mathrm{x}, \mu_{\mathrm{A}}(\mathrm{x}), 1-\mu_{\mathrm{A}}(\mathrm{x})>\mathrm{x} \square \mathrm{X}\right\} .
$$

Definition 1.2. [2] Let $A$ and $B$ are IFSs of the form $A=\{<x, \mu A(x), v A(x)>: x \square X\}$ and $\mathrm{B}=\{<\mathrm{x}, \mu \mathrm{B}(\mathrm{x}), v \mathrm{~B}(\mathrm{x})>: \mathrm{x} \square \mathrm{X}\}$. Then

(i) $\mathrm{A} \square \mathrm{B}$ if and only if $\mu_{\mathrm{A}}(\mathrm{x}) \leq \mu \mathrm{B}$ ( $\left.\mathrm{x}\right)$ and $v_{\mathrm{A}}(\mathrm{x}) \geq v_{\mathrm{B}}(\mathrm{x})$;

(ii) $\mathrm{A}=\left\{<\mathrm{x}, \mu_{\mathrm{A}}(\mathrm{x}), v_{\mathrm{A}}(\mathrm{x})>: \mathrm{x} \square \mathrm{X}\right\}$

(iii) $\mathrm{A} \cap \mathrm{B}=\{<\mathrm{x}, \mu \mathrm{A}(\mathrm{x}) \wedge \mu \mathrm{B}(\mathrm{x}), v \mathrm{~A}(\mathrm{x}) \vee v \mathrm{~B}(\mathrm{x})>$ : $\mathrm{x} \square \mathrm{X}\}$; (iv) $\mathrm{A} \vee \mathrm{B}=\left\{<\mathrm{x}, \mu_{\mathrm{A}}(\mathrm{x}) \vee \mu \mathrm{B}\right.$ (x), $\left.v \mathrm{~A}(\mathrm{x}) \wedge v_{\mathrm{B}}(\mathrm{x})>: \mathrm{x} \square \mathrm{X}\right\} ;(\mathrm{v}) \mathrm{A}=\mathrm{B}$ iff $\mathrm{A} \square \mathrm{B}$ and $\mathrm{B} \square \mathrm{A}$;

(vi) [] $\mathrm{A}=\left\{<\mathrm{x}, \mu_{\mathrm{A}}(\mathrm{x}), 1-\mu_{\mathrm{A}}(\mathrm{x})>: \mathrm{x} \square \mathrm{X}\right\}$; (vii) $>\mathrm{A}=\left\{<\mathrm{x}, 1-v_{\mathrm{A}}(\mathrm{x}), v_{\mathrm{A}}(\mathrm{x})>: \mathrm{x} \square \mathrm{X}\right\}$;

(viii) $1 \sim=\{<\mathrm{X}, 1,0>, \mathrm{X} \square \mathrm{X}\}$ and $0 \sim=\{<\mathrm{X}, 0,1>, \mathrm{X} \square \mathrm{X}\}$.

We will use the notation $A=<x, \mu_{A}(x), v A(x)>$ instead of $A=\{<x, \mu A(x), v A(x)>, x \square X\}$. Definition 1.3. [10] A family $\tau$ of IFsS's on $X$ called an instuitionistic fuzzy supra topology (IFsT for short) on $\mathrm{X}$ if $0_{\sim} \square \tau, 1_{\sim} \square \tau$ and $\tau$ is closed under arbitrary suprema. Then we call the pair $(X, \tau)$ an instuitionistic fuzzy supra topological space (IFsTS for short). Each member of $\tau$ is called an instuitionis- tic fuzzy supra open set and the complement of instuitionistic fuzzy supra open set is called instuitionistic fuzzy supra closed set. The instuitionistic fuzzy supra closure of an IFsS A is denoted by scl(A). Here $\mathrm{s}-\mathrm{cl}(\mathrm{A})$ is the intersection of all instuitionistic fuzzy supra closed sets containing A. The instuitionistic fuzzy supra interior of A will be denoted by s-int(A). Here, s-int(A) is the union of all instuitionistic fuzzy supra open sets contained in A.

Definition 1.4. Let $(\mathrm{X}, \tau)$ be an instuitionistic fuzzy supra topological space. An IFS A IF (X)

is called

(i) instuitionistic fuzzy supra $\alpha$-open [7] iff A $\square$ s-int(s-cl(s-int(A))),

(ii) instuitionistic fuzzy supra $\beta$-open [6] iff $\mathrm{A} \square \mathrm{s}-\mathrm{cl}(\mathrm{s}-\mathrm{int}(\mathrm{s}-\mathrm{cl}(\mathrm{A})))$,

(iii) instuitionistic fuzzy supra b-open [6] iff A $\square \mathrm{s}-\operatorname{int}(\mathrm{s}-\mathrm{cl}(\mathrm{A})) \cup \mathrm{s}-\mathrm{cl}(\mathrm{s}-\mathrm{int}(\mathrm{A}))$, 
Let $\mathbf{f}$ be a mapping from an ordinary set $\mathrm{X}$ into an ordinary set $\mathrm{Y}$, if $\mathrm{B}=$

$\left\{<\mathrm{y}, \mu_{\mathrm{A}}(\mathrm{y}), v \mathrm{~B}(\mathrm{y})>: \mathrm{y} \square \mathrm{Y}\right\}$ is an IFsT in $\mathrm{Y}$, then the inverse image of $\mathrm{B}$ under $\mathbf{f}$

is an IFsT defined by $\mathrm{f}^{-1}(\mathrm{~B})=\left\{<\mathrm{x}, \mathrm{f}^{-1}\left(\mu_{\mathrm{B}}\right)(\mathrm{x}), \mathrm{f}^{-1}\left(v_{\mathrm{B}}\right)(\mathrm{x})>: \mathrm{x} \square \mathrm{X}\right\}$.

$\quad$ The image of IFsT $A=\{<y, \mu A(y), v A(y)>: y \square Y\}$ under $\mathbf{f}$ is an IFsT defined by $f(A)$
$\left\{<y, f\left(\mu_{A}(y)\right), f(v A(y))>: y \square Y\right\}$.

\section{Intuitionistic fuzzy supra pre-open set.}

In this section, we introduce a new class of open sets called intuitionistic fuzzy supra preopen sets and study some of their basic properties.

Definition 2.1. Let $(X, \tau)$ be an intuitionistic fuzzy supratopological space. An intuitionistic fuzzy set $\mathrm{A}$ is called an intuitionistic fuzzy supra pre-open set (briefly IFsPOS) if A $\square \mathrm{s}$-int(s-cl(A)). The complement of an intuitionistic fuzzy supra pre-open set is called an intuitionistic fuzzy supra pre-closed set (briefly IFsPCS).

Theorem 2.2. Every intuitionistic fuzzy supra-open set is an intuitionistic fuzzy supra pre-open.

Proof. Let $A$ be an intuitionistic fuzzy supra-open set in $(X, \tau)$. Then $A \square \operatorname{s-int}(A)$, we get $A \square \mathrm{s}-\operatorname{int}(\mathrm{s}-\mathrm{cl}(\mathrm{A}))$ then $\mathrm{s}-\operatorname{int}(\mathrm{A}) \square \mathrm{s}-\operatorname{int}(\mathrm{s}-\mathrm{cl}(\mathrm{A}))$. Hence $\mathrm{A}$ is supra pre-open in $(\mathrm{X}, \tau)$.

The converse of the above theorem need not be true as shown by the following example.

Example 2.3. Let $\mathrm{X}=\{\mathrm{a}, \mathrm{b}\}, \mathrm{A}=\{\mathrm{x},<0.5,0.2>,<0.3,0.4>\}$,

$\mathrm{B}=\{\mathrm{x},<0.3,0.4>,<0.6,0.5>\}$ and $\mathrm{C}=\{\mathrm{x},<0.3,0.4>,<0.2,0.5>\}$,

$\tau=\{0 \sim, 1 \sim, \mathrm{A}, \mathrm{B}, \mathrm{A} \cup \mathrm{B}\}$. Then $\mathrm{C}$ is called intuitionistic fuzzy supra pre-open set but it is not an intuitionistic fuzzy supra-open set.

Theorem 2.4. Every intuitionistic fuzzy supra $\alpha$-open set is an intuitionistic fuzzy supra pre-open

Proof. Let A be an intuitionistic fuzzy supra $\alpha$-open set in $(X, \tau)$. Then A $\square$ s-int(s$\operatorname{cl}(\mathrm{s}-\mathrm{int}(\mathrm{A}))$, it is obvious that $\mathrm{s}-\operatorname{int}(\mathrm{s}-\mathrm{cl}(\mathrm{s}-\operatorname{int}(\mathrm{A})) \square \mathrm{s}-\operatorname{int}(\mathrm{s}-\mathrm{cl}(\mathrm{A}))$ and $\mathrm{A} \quad \square \mathrm{s}-\mathrm{int}(\mathrm{s}-$ $\operatorname{cl}(\mathrm{A}))$. Hence $\mathrm{A}$ is an intuitionistic fuzzy supra pre-open in $(\mathrm{X}, \tau)$.

The converse of the above theorem need not be true as shown by the following example. Example 2.5. Let $X=\{a, b\}, A=\{x,<0.3,0.5>,<0.4,0.5>\}$,

$\mathrm{B}=\{\mathrm{x},<0.4,0.3>,<0.5,0.4>\}$ and $\mathrm{C}=\{\mathrm{x},<0.4,0.5>,<0.5,0.4>\}$,

$\tau=\{0 \sim, 1 \sim, \mathrm{A}, \mathrm{B}, \mathrm{A} \cup \mathrm{B}\}$. Then $\mathrm{C}$ is called an intuitionistic fuzzy supra pre-open set but it is not an intuitionistic fuzzy supra $\alpha$-open set.

Theorem 2.6. Every intuitionistic fuzzy supra pre-open set is an intuitionistic fuzzy supra $\beta$-open

Proof. Let $A$ be an intuitionistic fuzzy supra pre-open set in $(X, \tau)$. It is obvious that s-int(s-cl(A)) $\square \mathrm{s}-\mathrm{cl}(\mathrm{s}-\mathrm{int}(\mathrm{s}-\mathrm{cl}(\mathrm{A})))$. Then $\mathrm{A} \quad \square \mathrm{s}-\operatorname{int}(\mathrm{s}-\mathrm{cl}(\mathrm{A}))$. Hence A $\square \mathrm{s}-\mathrm{cl}(\mathrm{s}-$ $\operatorname{int}(\mathrm{s}-\mathrm{cl}(\mathrm{A})))$. 
The converse of the above theorem need not be true as shown by the following example. Example 2.7. Let $\mathrm{X}=\{\mathrm{a}, \mathrm{b}\}, \mathrm{A}=\{\mathrm{x},<0.2,0.3>,<0.5,0.3>\}$,

$\mathrm{B}=\{\mathrm{x},<0.1,0.2>,<0.6,0.5>\}$ and $\mathrm{C}=\{\mathrm{x},<0.2,0.3>,<0.2,0.3>\}$,

$\tau=\{0 \sim, 1 \sim, \mathrm{A}, \mathrm{B}, \mathrm{A} \cup \mathrm{B}\}$. Then $\mathrm{C}$ is called an intuitionistic fuzzy supra pre-open set but it is not an intuitionistic fuzzy supra pre-open set.

Theorem 2.8. Every intuitionistic fuzzy supra pre-open set is an intuitionistic fuzzy supra b-open

Proof. Let $A$ be an intuitionistic fuzzy supra pre-open set in $(X, \tau)$. It is obvious that $A \square \mathrm{s}-\operatorname{int}(\mathrm{s}-\mathrm{cl}(\mathrm{A})) \square \mathrm{s}-\operatorname{int}(\mathrm{s}-\mathrm{cl}(\mathrm{A})) \cup \mathrm{s}-\mathrm{cl}(\mathrm{s}-\operatorname{int}(\mathrm{A})))$, Then $\mathrm{A} \square \mathrm{s}-\operatorname{int}(\mathrm{s}-\mathrm{cl}(\mathrm{A}))$. Hence A $\square \mathrm{s}-\mathrm{int}(\mathrm{s}-\mathrm{cl}(\mathrm{A})) \cup \mathrm{s}-\mathrm{cl}(\mathrm{s}-\mathrm{int}(\mathrm{A})))$.

The converse of the above theorem need not be true as shown by the following example.

Example 2.9. Let $\mathrm{X}=\{\mathrm{a}, \mathrm{b}\}, \mathrm{A}=\{\mathrm{x},<0.5,0.2>,<0.3,0.4>\}, \mathrm{B}=\{\mathrm{x},<0.3,0.4>,<0.6$, $0.5>\}$ and $\mathrm{C}=\{\mathrm{x},<0.3,0.4>,<0.4,0.4>\}, \tau=\{0 \square, 1 \square, \mathrm{A}, \mathrm{B}, \mathrm{A} \cup \mathrm{B}\}$. Then $\mathrm{C}$ is called an intuitionistic fuzzy supra pre-open set but it is not an intuitionistic fuzzy supra pre-open set.

\section{IFsOS $\rightarrow$ IFs $\alpha \mathrm{OS}$}

$\& \quad \downarrow$

IFsbOS $\leftarrow$ IFsPOS $\rightarrow$ IFs $\beta$ OS

Theorem 2.10.

(i) Arbitrary union of intuitionistic fuzzy supra pre-open sets is always an in- tuitionistic fuzzy supra pre-open.

(ii) Finite intersection of intuitionistic fuzzy supra pre-open sets may fail to be an intuitionistic fuzzy supra pre-open.

(iii) $\mathrm{X}$ is an intuitionistic fuzzy supra pre-open set.

Proof.

(i) Let $\mathrm{A}$ and $\mathrm{B}$ to be intuitionistic fuzzy supra pre-open sets. Then $\mathrm{A} \square \mathrm{s}$-int(s-cl(A)) and $\mathrm{B} \square \mathrm{s}-\operatorname{int}(\mathrm{s}-\mathrm{cl}(\mathrm{B}))$. Then $\mathrm{A} \cup \mathrm{B} \square \mathrm{s}-\mathrm{int}(\mathrm{s}-\mathrm{cl}(\mathrm{A}))$. Therefore, $\mathrm{A} \cup \mathrm{B} \square \mathrm{s}-\operatorname{int}(\mathrm{s}-\mathrm{cl}(\mathrm{A}$ $\vee \mathrm{B})) \square \mathrm{s}-\operatorname{int}((\mathrm{s}-\mathrm{cl}(\mathrm{A} \cup \mathrm{B}))) \quad \square \mathrm{s}-\operatorname{int}(\mathrm{s}-\mathrm{cl}(\vee(\mathrm{A} \cup \mathrm{B})))$ is an intuitionistic fuzzy supra preopen sets.

(ii) Let $\mathrm{X}=\{\mathrm{a}, \mathrm{b}\}, \mathrm{A}=\{\mathrm{x},<0.3,0.4>,<0.2,0.5>\}, \mathrm{B}=\{\mathrm{x},<0.3,0.4>,<0.4,0.4>\}$ and $\tau=$ $\{0 \sim, 1 \sim, A, B, A \cup B\}$. Hence $A$ and $B$ are intuitionistic fuzzy supra pre-open but $A \cap B$ is not intuitionistic fuzzy supra pre-open set.

Theorem 2.11.

(i) Arbitrary intersection of intuitionistic fuzzy supra pre-closed sets is always an intuitionistic fuzzy supra pre-closed. 
(ii) Finite union of intuitionistic fuzzy supra pre-closed sets may fail to be an intuitionistic fuzzy supra pre-closed.

Proof.

(i) This proof immediately from Theorem 2.10

(ii) Let $\mathrm{X}=\{\mathrm{a}, \mathrm{b}\}, \mathrm{A}=\{\mathrm{x},<0.2,0.3>,<0.2,0.4>\}, \mathrm{B}=\{\mathrm{x},<0.5,0.4>,<0.4,0.5>\}$ and $\tau=$ $\{0 \sim, 1 \sim, A, B, A \cup B\}$. Hence $A$ and $B$ are intuitionistic fuzzy supra pre-closed but $A \cup B$ is not an intuitionistic fuzzy supra pre-closed set.

Definition 2.12. The intuitionistic fuzzy supra pre-closure of a set A, denoted by s-pre$\mathrm{cl}(\mathrm{A})$, is the intersection of an intuitionistic fuzzy supra pre-closed sets including A. The intuitionistic fuzzy supra pre-interior of a set $A$, denoted by s-pre-int(A), is the union of intuitionistic fuzzy supra pre-open sets included in A.

Remark 2.13. It is clear that s-pre-int(A) is an intuitionistic fuzzy supra pre-open set and s-pre-cl(A) is an intuitionistic fuzzy supra pre-closed set.

Theorem 2.14.

(i) $\mathrm{A} \square \mathrm{s}-\operatorname{pre}-\mathrm{cl}(\mathrm{A})$; and $\mathrm{A}=\mathrm{s}-\operatorname{pre}-\mathrm{cl}(\mathrm{A})$ iff $\mathrm{A}$ is an intuitionistic fuzzy supra pre-closed set;

(ii) $\quad$ s-pre-int(A) $\square \mathrm{A}$; and s-pre-int(A) $=\mathrm{A}$ iff $\mathrm{A}$ is an intuitionistic fuzzy suprapre-open set;

(iii) $\mathrm{X}-\mathrm{s}-\operatorname{pre}-\operatorname{int}(\mathrm{A})=\mathrm{s}-\operatorname{pre}-\mathrm{cl}(\mathrm{X}-\mathrm{A})$;

(iv) $\mathrm{X}-\mathrm{s}-\operatorname{pre}-\mathrm{cl}(\mathrm{A})=\mathrm{s}-$ pre-int $(\mathrm{X}-\mathrm{A})$.

Proof. Obvious.

Theorem 2.15 .

(i) s-pre-int(A) $\cup$ s-pre-int(B) $\square$ s-pre-int(A $\vee$ B); (i) s-pre-cl(A $\cap$ B) $\square$ s-pre-cl(A) $\cap$ spre-cl(B).

Proof. Obvious.

The inclusions in (i) and (ii) in Theorem 2.15 can not replaced by equalities by let $\mathrm{X}=$ $\{\mathrm{a}, \mathrm{b}\}, \mathrm{A}=\{\mathrm{x},<0.3,0.4>,<0.2,0.5>\}, \mathrm{B}=\{\mathrm{x},<0.3,0.4>,<0.4,0.4>\}$ and $\tau=\left\{0_{\sim}, 1_{\sim}, \mathrm{A}\right.$, $\mathrm{B}, \mathrm{A} \cup \mathrm{B}\}$, where s-pre-int $(\mathrm{A})=\{\mathrm{x},<0.2,0.5>,<0.3,0.4>\}$, s-pre- $\operatorname{int}(\mathrm{B})=\{\mathrm{x},<0.5,0.4>$, $<0.4,0.5>\}$ and s-pre-int $(\mathrm{A} \vee \mathrm{B})=\{\mathrm{x},<0.5,0.5>,<0.3,0.4>\}$. Then s-pre-cl(A) $\cap$ s-pre-cl(B) $=\{\mathrm{x},\langle 0.3,0.4>,\langle 0.2,0.5>\}$ and $\mathrm{s}-\mathrm{pre}-\mathrm{cl}(\mathrm{A})=\mathrm{s}-\mathrm{pre}-\mathrm{cl}(\mathrm{B})=1 \sim$.

Proposition 2.16 .

(i) The intersection of an intuitionistic fuzzy supra open set and an intuitionistic fuzzy supra pre-open set is an intuitionistic fuzzy supra pre-open set

(ii) The intersection of an intuitionistic fuzzy supra $\alpha$-open set and an intu- itionistic fuzzy supra pre-open set is an intuitionistic fuzzy supra pre-open set

\section{Intuitionistic suzzy supra pre-continuous mappings.}

In this section, we introduce a new type of continuous mapings called a intu- itionistic 
fuzzy supra pre-continuous mappings and obtain some of their properties and characterizations.

Definition 3.1. Let $(\mathrm{X}, \tau)$ and $(\mathrm{Y}, \sigma)$ be the two intuitionistic fuzzy topolog- ical sets and $\mu$ be an associated supra topology with $\tau$. A map $f:(X, \tau) \rightarrow(Y, \sigma)$ is called an intuitionistic fuzzy supra pre-continuous mapping if the inverse image of each open set in $\mathrm{Y}$ is an intuitionistic fuzzy supra pre-open set in $\mathrm{X}$.

Theorem 3.2. Every intuitionistic fuzzy supra continuous map is an intu- itionistic fuzzy supra pre-continuous map .

Proof. Let $\mathrm{f}:(\mathrm{X}, \tau) \rightarrow(\mathrm{Y}, \sigma)$ is called intuitionistic fuzzy continuous map

and $A$ is an IFsOS in $Y$. Then $f^{-1}(A)$ is an IFsOS in $X$. Since $\mu$ is associated with $\tau$, then $\tau \square \mu$. Therefore, $\mathrm{f}^{-1}(\mathrm{~A})$ is an IFsOS in $\mathrm{X}$ which is an IFsPOS set in $\mathrm{X}$. Hence $\mathrm{f}$ is an intuitionistic fuzzy supra pre-continuous map.

The converse of the above theorem is not true as shown in the following exam ple.

Example 3.3. Let $\mathrm{X}=\{\mathrm{a}, \mathrm{b}\}, \mathrm{Y}=\{\mathrm{u}, \mathrm{v}\}$ and $\mathrm{A}=\{<0.5,0.2>,<0.3,0.4>\}$,

$\mathrm{B}=\{<0.3,0.4>,<0.6,0.5>\}, \mathrm{C}=\{<0.5,0.4>,<0.3,0.4>\}, \mathrm{D}=\{<0.3,0.4>,<0.6,0.5>\}$. Then $\tau=\left\{0_{\sim}, 1_{\sim}, \mathrm{A}, \mathrm{B}, \mathrm{A} \vee \mathrm{B}\right\}$ be an intuitionistic fuzzy supra topology on $\mathrm{X}$. Then the intuitionistic fuzzy supra topology $\sigma$ on $\mathrm{Y}$ is defined as follows: $\sigma=\{0 \sim, 1 \sim, \mathrm{C}, \mathrm{D}, \mathrm{C} v$ $\mathrm{D}\}$. Define a mapping $\mathrm{f}(\mathrm{X}, \tau) \rightarrow(\mathrm{Y}, \sigma)$ by $\mathrm{f}(\mathrm{a})=\mathrm{u}$ and $\mathrm{f}(\mathrm{b})=\mathrm{v}$. The inverse image of the IFsOS in $\mathrm{Y}$ is not an IFsOS in $\mathrm{X}$ but it is an IFsPOS. Then $\mathbf{f}$ is an intuitionistic fuzzy supra pre-continuous map but not be an intuitionistic fuzzy supra continuous map.

Theorem 3.4. Every intuitionistic fuzzy supra $\alpha$-continuous map is an intu- itionistic fuzzy supra pre-continuous map .

Proof. Let $\mathrm{f}:(\mathrm{X}, \tau) \rightarrow(\mathrm{Y}, \sigma)$ is called intuitionistic fuzzy supra $\alpha$-continuous

map and $A$ is an IFsOS in $Y$. Then $\mathrm{f}^{-1}(\mathrm{~A})$ is an IFs $\alpha \mathrm{OS}$ in $\mathrm{X}$. Since $\mu$ is as- sociated with $\tau$, then $\tau \square \mu$. Therefore, $\mathrm{f}^{-1}(\mathrm{~A})$ is an IFsaOS in $\mathrm{X}$ which is an IFsPOS in $\mathrm{X}$. Hence $\mathbf{f}$ is an intuitionistic fuzzy supra pre-continuous map.

The converse of the above theorm is not true as shown in the following exam- ple.

Example 3.5. Let $\mathrm{X}=\{\mathrm{a}, \mathrm{b}\}, \mathrm{Y}=\{\mathrm{u}, \mathrm{v}\}$ and $\mathrm{A}=\{<0.5,0.2>,<0.3,0.4>\}$, $\mathrm{B}=\{<0.3,0.4>,<0.6,0.5>\}, \mathrm{C}=\{<0.5,0.4>,<0.3,0.4>\}, \mathrm{D}=\{<0.3,0.4>,<0.6,0.5>\}$. Then $\tau=\{0 \sim, 1 \sim, A, B, A \cup B\}$ be an intuitionistic fuzzy supra topology on $\mathrm{X}$. Then the intuitionistic fuzzy supra topology $\sigma$ on $\mathrm{Y}$ is defined as follows: $\sigma=\{0 \sim, \sim, \mathrm{C}, \mathrm{D}, \mathrm{C} v$ $D\}$. Define a mapping $f(X, \tau) \rightarrow(Y, \sigma)$ by $f(a)=u$ and $f(b)=v$. The inverse image of IFsOS in $\mathrm{Y}$ is not an IFs $\alpha \mathrm{OS}$ in $\mathrm{X}$ but it is an IFsPOS. Then $\mathbf{f}$ is an intuitionistic fuzzy supra pre-continuous map but not be an intuitionistic fuzzy supra $\alpha$-continuous map.

Theorem 3.6. Every intuitionistic fuzzy supra pre-continuous map is an in- tuitionistic fuzzy supra b-continuous map .

Proof. Let $\mathrm{f}:(\mathrm{X}, \tau) \rightarrow(\mathrm{Y}, \sigma)$ is called intuitionistic fuzzy supra pre- continuous map and $A$ is an IFsOS in $Y$. Then $f^{-1}(A)$ is an IFsPOS in $X$. Since $\mu$ is associated with $\tau$, then $\tau \square \mu$. Therefore, $\mathrm{f}^{-1}(\mathrm{~A})$ is an IFsPOS in $\mathrm{X}$ which is an IFsbOS in $\mathrm{X}$. Hence $\mathrm{f}$ is an intuitionistic fuzzy supra b-continuous map.

The converse of the above theorm is not true as shown in the following exam- ple. 
Example 3.7. Let $\mathrm{X}=\{\mathrm{a}, \mathrm{b}\}, \mathrm{Y}=\{\mathrm{u}, \mathrm{v}\}$ and $\mathrm{A}=\{<0.5,0.2>,<0.3,0.4>\}$, $\mathrm{B}=\{<0.3,0.4>,<0.6,0.5>\}, \mathrm{C}=\{<0.5,0.4>,<0.3,0.4>\}, \mathrm{D}=\{<0.3,0.4>,<0.6,0.5>\}$. Then $\tau=\{0 \sim, 1 \sim, A, B, A \cup B\}$ be an intuitionistic fuzzy supra topology on $\mathrm{X}$. Then the intuitionistic fuzzy supra topology $\sigma$ on $\mathrm{Y}$ is defined as follows: $\sigma=\left\{0_{\sim}, 1 \sim, \mathrm{C}, \mathrm{D}, \mathrm{C}\right.$ $\vee \mathrm{D}\}$. Then $\tau=\{0 \square, 1 \square, \mathrm{A}, \mathrm{B}, \mathrm{A} \cup \mathrm{B}\}$ be an intuitionistic fuzzy supra topology on $\mathrm{X}$. Then the intuitionistic fuzzy supra topology $\sigma$ on $\mathrm{Y}$ is defined as follows: $\sigma=\left\{0_{\sim}\right.$, $1 \sim, \mathrm{C}, \mathrm{D}, \mathrm{C} \cup \mathrm{D}\}$. Define a mapping $\mathrm{f}(\mathrm{X}, \tau) \rightarrow(\mathrm{Y}, \sigma)$ by $\mathrm{f}(\mathrm{a})=\mathrm{u}$ and $\mathrm{f}(\mathrm{b})=\mathrm{v}$. The inverse image of IFsOS in $\mathrm{Y}$ is not an IFsPOS in $\mathrm{X}$ but it is an IFsbOS. Then $\boldsymbol{f}$ is an intuitionistic fuzzy supra b-continuous map but not be an intuitionistic fuzzy supra precontinuous map.

Theorem 3.8. Every intuitionistic fuzzy supra pre-continuous map is an in- tuitionistic fuzzy supra $\beta$-continuous map .

Proof. Let $\mathrm{f}:(\mathrm{X}, \tau) \rightarrow(\mathrm{Y}, \sigma)$ is called intuitionistic fuzzy supra pre-

continuous map and $A$ is an IFsOS in $Y$. Then $f^{-1}(A)$ is an IFsPOS in $X$. Since $\mu$ is associated with $\tau$, then $\tau \square \mu$. Therefore, $\mathbf{f}^{-1}(\mathrm{~A})$ is an IFsPOS in $\mathrm{X}$ which is an IFs $\beta O S$ in $X$. Hence $f$ is an intuitionistic fuzzy supra $\beta$-continuous map.

The converse of the above theorem is not true as shown in the following exam ple.

Example 3.9. Let $\mathrm{X}=\{\mathrm{a}, \mathrm{b}\}, \mathrm{Y}=\{\mathrm{u}, \mathrm{v}\}$ and $\mathrm{A}=\{<0.5,0.2>,<0.3,0.4>\}$, $\mathrm{B}=\{<0.3,0.4>,<0.6,0.5>\}, \mathrm{C}=\{<0.5,0.2>,<0.3,0.4>\}, \mathrm{D}=\{<0.3,0.4>,<0.6,0.5>\}$. Then $\tau=\left\{0_{\sim}, 1 \sim, \mathrm{A}, \mathrm{B}, \mathrm{A} \cup \mathrm{B}\right\}$ be an intuitionistic fuzzy supra topology on $\mathrm{X}$. Then the intuitionistic fuzzy supra topology $\sigma$ on $\mathrm{Y}$ is defined as follows: $\sigma=\{0 \sim, 1 \sim, \mathrm{C}, \mathrm{D}, \mathrm{C} v$ $\mathrm{D}\}$. Define a mapping $\mathrm{f}(\mathrm{X}, \tau) \rightarrow(\mathrm{Y}, \sigma)$ by $\mathrm{f}(\mathrm{a})=\mathrm{u}$ and $\mathrm{f}(\mathrm{b})=\mathrm{v}$. The inverse image of IFsOS in $\mathrm{Y}$ is not an IFsPOS in $\mathrm{X}$ but it is an IFs $\beta O S$. Then $\mathrm{f}$ is an intuitionistic fuzzy supra b-continuous map but not be an intuitionistic fuzzy supra pre-continuous map.

IFs continuous $\rightarrow$ IFs $\alpha$ continuous

$\& \quad \downarrow$

IFsb continuous $\leftarrow$ IFsP continuous $\rightarrow$ IFs $\beta$ continuous

Theorem 3.10. Let $(\mathrm{X}, \tau)$ and $(\mathrm{Y}, \sigma)$ be the two topological spaces and $\mu$ be an associated intuitionistic fuzzy supra topology with $\tau$. Let $f$ be a map from $X$ into $Y$. Then the following are equivalent

(i) $\mathbf{f}$ is an intuitionistic fuzzy supra pre-continuous map.

(ii) The inverse image of an intuitionistic fuzzy supra closed sets in $Y$ is an intuitionistic fuzzy supra pre-closed set in $\mathrm{X}$;

(iii) s-pre-cl( $\left.\mathrm{f}^{-1}(\mathrm{~A})\right) \square \mathrm{f}^{-1}(\mathrm{cl}(\mathrm{A}))$ for every set $\mathrm{A}$ inY;

(iv) $f(s-p r e-c l(A)) \square \operatorname{cl}(f(A))$ for every set $A$ in $X$;

(v) $\mathbf{f}^{-1}(\operatorname{int}(\mathrm{B})) \square$ s-pre-int $\left(\mathrm{f}^{-1}(\mathrm{~B})\right)$ for every set $\mathrm{B}$ in $\mathrm{Y}$.

Proof. (i) $\Rightarrow$ (ii): Let $A$ be a closed set in $Y$, then $Y-A$ is open set in $Y$. Then $f^{-1}(Y$ $-\mathrm{A})=\mathrm{X}-\mathrm{f}^{-1}(\mathrm{~A})$ is s-pre-open set in $\mathrm{X}$. It follows that $\mathrm{f}^{-1}(\mathrm{~A})$ is a supra pre-closed subset of $X$. 
(ii) $\Rightarrow$ (iii): Let $A$ be any subset of $Y$. Since $\operatorname{cl}(A)$ is closed in $Y$, then it follows that $\mathbf{f}$

$-1(\operatorname{cl}(\mathrm{A}))$ is an intuitionistic fuzzy supra pre-closed set in $\mathrm{X}$. Therefore s-pre-cl(f $-1(\mathrm{~A})) \square\left(\mathrm{f}^{-1}(\mathrm{cl}(\mathrm{A}))\right)=\left(\mathrm{f}^{-1}(\mathrm{cl}(\mathrm{A}))\right.$.

(iii) $\Rightarrow$ (iv): Let $A$ be any subset of $X$. By (iii) we have $\mathrm{f}^{-1}(\mathrm{cl}(\mathrm{f}(\mathrm{A}))) \square \operatorname{s-pre-cl}\left(\mathrm{f}^{-1}\right.$ (f (A))) $\square$ s-pre-cl(A) and hence $\mathrm{f}(\mathrm{s}-\operatorname{pre}-\mathrm{cl}(\mathrm{A})) \square \mathrm{cl}(\mathrm{f}(\mathrm{A}))$.

(iv) $\Rightarrow(v)$ : Let $B$ be any subset of $Y$. By (4) we have $\mathrm{f}^{-1}\left(\mathrm{~s}-\operatorname{pre}-\mathrm{cl}\left(\mathrm{X}-\mathrm{f}^{-1}(\mathrm{~B})\right)\right) \square \operatorname{cl}(\mathrm{f}(\mathrm{X}$ $\left.\left.-f^{-1}(B)\right)\right)$ and $f\left(X-s-p r e-i n t\left(f^{-1}(B)\right)\right) \square c l(Y-B)=Y-i n t(B)$. There- fore we have $X-s-$ $\operatorname{pre}-i n t\left(f^{-1}(B)\right) \square \mathbf{f}^{-1}(Y-\operatorname{int}(B))$ and hence $f^{-1}(\operatorname{int}(B)) \square$ s- pre-int $\left(f^{-1}(B)\right)$.

$(\mathrm{v}) \Rightarrow(\mathrm{i})$ : Let $\mathrm{B}$ be a open set in $\mathrm{Y}$ and $\mathrm{f}^{-1}(\operatorname{int}(\mathrm{B})) \square$ s-pre-int $\left(\mathrm{f}^{-1}(\mathrm{~B})\right)$, hence $\mathrm{f}^{-1}(\mathrm{~B})$ $\square$ s-pre-int $\left(\mathrm{f}^{-1}(\mathrm{~B})\right)$. Then $\mathrm{f}^{-1}(\mathrm{~B})=$ s-pre-int $\left(\mathrm{f}^{-1}(\mathrm{~B})\right)$. But, s-pre- $\operatorname{int}\left(\mathrm{f}^{-1}(\mathrm{~B})\right) \square \mathrm{f}$ $-1(B)$. Hence $\mathrm{f}^{-1}(\mathrm{~B})=\operatorname{s-pre-int}\left(\mathrm{f}^{-1}(\mathrm{~B})\right)$. Therefore $\mathrm{f}^{-1}(\mathrm{~B})$ is an intuitionistic fuzzy supra pre-open set in $\mathrm{Y}$.

Theorem 3.11. If a map $\mathrm{f}:(\mathrm{X}, \tau) \rightarrow(\mathrm{Y}, \sigma)$ is a s-pre-continuous and

$\mathrm{g}:(\mathrm{Y}, \sigma) \rightarrow(\mathrm{Z}, \eta)$ is continuous ,then $(\mathrm{g} \circ \mathrm{f})$ is s-pre-continuous.

Proof. Obvious.

Theorem 3.12. Let $\mathrm{f}:(\mathrm{X}, \tau) \rightarrow(\mathrm{Y}, \sigma)$ be an intuitionistic fuzzy s-pre- continuous map if one of the following holds:

(i) $\mathrm{f}^{-1}\left(\mathrm{~s}-\right.$ pre-int(B)) $\square \operatorname{int}\left(\mathrm{f}^{-1}(\mathrm{~B})\right)$ for every set $\mathrm{B}$ in $\mathrm{Y}$, (ii) $\operatorname{cl}\left(\mathrm{f}^{-1}(\mathrm{~A})\right) \square \mathrm{f}^{-1}$ (s-pre$\mathrm{cl}(\mathrm{B}))$ for every set $\mathrm{B}$ in $\mathrm{Y}$,

(iii) $\mathrm{f}(\mathrm{cl}(\mathrm{A})) \square \mathrm{s}-\operatorname{pre}-\mathrm{cl}(\mathrm{f}(\mathrm{B}))$ for every $\mathrm{A}$ in $\mathrm{X}$.

Proof. Let $B$ be any open set of $Y$, if the condition (i) is satisfied, then $f^{-1}$ (s- pre-int(B)) $\square \operatorname{int}\left(f^{-1}(B)\right)$. We get, $f^{-1}(B) \square \operatorname{int}\left(f^{-1}(B)\right)$. Therefore

$\mathrm{f}^{-1}$ (B) is an intuitionistic fuzzy open set. Every intuitionistic fuzzy open set is intuitionistic fuzzy supra pre-open set. Hence $f$ is an intuitionistic fuzzy s-pre-continuous . If condition (ii) is satisfied, then we can easily prove that $f$ is an intuitionistic fuzzy supra pre-continuous. Let condition (iii) is satisfied and $B$ be any open set in $Y$. Then $\mathrm{f}^{-1}(\mathrm{~B})$ is a set in $\mathrm{X}$ and then we can easily prove that $\mathrm{f}$ is an intuitionistic fuzzy spre- continuous function. If condition (iii) is satisfied, and $B$ is any open set of $Y$. Then $\mathrm{f}^{-1}(\mathrm{~B})$ is a set in $\mathrm{X}$ and $\mathrm{f}\left(\mathrm{cl}\left(\mathrm{f}^{-1}(\mathrm{~B})\right)\right) \quad \square$ s-pre-cl( $\left(\mathrm{f}\left(\mathrm{f}^{-1}(\mathrm{~B})\right)\right)$. This implies $\mathrm{f}(\mathrm{cl}(\mathrm{f}$ $-1(\mathrm{~B}))) \quad \square \mathrm{s}-$ pre-cl(B). This is nothing but condition (ii). Hence $\mathrm{f}$ is an intuitionistic fuzzy s-pre-continuous.

\section{Intuitionistic Fuzzy supra pre-open maps and supra pre-closed maps.}

Definition 4.1. A map $\mathbf{f}: \mathrm{X} \rightarrow \mathrm{Y}$ is called intuitionistic fuzzy supra pre-open (res.intuitionistic fuzzy supra pre-closed) if the image of each open (resp.closed) set in $\mathrm{X}$, is intuitionistic fuzzy supra pre-open(resp.intuitionistic fuzzy supra pre-closed) in $\mathrm{Y}$. 
Theorem 4.2. A map $\mathrm{f}: \mathrm{X} \rightarrow \mathrm{Y}$ is called an intuitionistic fuzzy supra pre-open if and only if $f(\operatorname{int}(A)) \square$ s-pre-int(A) for every set A in X.

Proof. Suppose that $\mathbf{f}$ is an intuitionistic fuzzy supra pre-open map. Since int $(A) \square \mathbf{f}$ (A). By hypothesis $f(\operatorname{int}(A))$ is an intuitionistic fuzzy supra pre-open set and s-pre-int $(f$ (A)) is the largest intuitionistic fuzzy supra pre-open set con- tained in $f(A)$, then $f$ (int(A)) $\square$ s-pre-int(f(A))

Conversely, Let $A$ be a open set in $X$. Then $f(\operatorname{int}(A)) \square$ s-pre-int(f(A)). Since

$\operatorname{int}(A)=A$, then $f(A) \square$ s-pre-int $(f(A))$. Therefore $f(A)$ is an intuitionistic fuzzy supra pre-open set in $\mathrm{Y}$ and $\mathrm{f}$ is an intuitionistic fuzzy supra pre-open.

Theorem 4.3. A map $\mathbf{f}: \mathrm{X} \longrightarrow \mathrm{Y}$ is called an intuitionistic fuzzy suprapre-closed if and only if $\mathrm{f}(\mathrm{cl}(\mathrm{A})) \square \mathrm{s}-\mathrm{pre}-\mathrm{cl}(\mathrm{A})$ for every set $\mathrm{A}$ in $\mathrm{X}$.

Proof. Suppose that $f$ is an intuitionistic fuzzy supra pre-closed map. Since for each set $A$ in $X, \operatorname{cl}(A)$ is closed set in $X$, then $f(c l(A))$ is an intuitionis- tic fuzzy supra preclosed set in $Y$. Also, since $f(A) \square f(c l(A))$, then s-pre- $\operatorname{cl}(f(A)) \square f(c l(A))$.

Conversely, Let A be a closed set in $X$. Since s-pre-cl(f(A)) is the smallest intuitionistic fuzzy supra pre-closed set containing $f(A)$, then $f(A) \square$ s-pre- $\operatorname{cl}(f(A))$ $\square \mathrm{f}(\mathrm{cl}(\mathrm{A}))=\mathrm{f}(\mathrm{A})$. Thus $\mathrm{f}(\mathrm{A})=$ s-pre-cl( $(\mathrm{f}(\mathrm{A}))$. Hence $\mathrm{f}(\mathrm{A})$ is an intuitionistic fuzzy supra pre-closed set in $Y$. Therefore $\mathbf{f}$ is a intuitionistic fuzzy supra pre-closed map.

Theorem 4.4. Let $\mathrm{f}: \mathrm{X} \rightarrow \mathrm{Y}$ and $\mathrm{g}: \mathrm{Y} \rightarrow \mathrm{Z}$ be two maps.

(i) If $g \circ f$ is an intuitionistic fuzzy supra pre-open and $f$ is continuous surjective, then $g$ is an intuitionistic fuzzy supra pre-open.

(ii) If $g \circ f$ is open and $g$ is an intuitionistic fuzzy supra precontinuous injective, then $\mathbf{f}$ is an intuitionistic fuzzy supra pre-open.

(iii) $\mathbf{f}$ is an intuitionistic fuzzy supra pre-closed map;

Proof. (i) $\Rightarrow$ (ii). Suppose B is a closed set in $X$. Then $X-B$ is an open set in an open set in $X$. By (1), $f(X-B)$ is an intuitionistic fuzzy supra pre-open set in $X$. Since $f$ is bijective, then $f(X-B)=Y-f(B)$. Hence $f(B)$ is an intuitionistic fuzzy supra preclosed set in $\mathrm{Y}$. Therefore $\mathrm{f}$ is an intuitionistic fuzzy supra pre-closed map.

(ii) $\Rightarrow$ (iii). Let $\mathbf{f}$ is an intuitionistic fuzzy supra pre-closed map and $\mathrm{B}$ be closed set $\mathrm{X}$.

Since $\mathbf{f}$ is bijective, then $\left(\mathrm{f}^{-1}\right)^{-1}(\mathrm{~B})=\mathbf{f}(\mathrm{B})$ is an intuitionistic fuzzy supra pre-closed set in $\mathrm{Y}$. By Theorem $3.7 \mathrm{f}$ is an intuitionistic fuzzy supra pre-continuous map.

(iii) $\Rightarrow$ (i). Let $A$ be an open set in $X$. Since $f^{-1}$ is an intuitionistic fuzzy supra precontinuous map, then $\left(\mathrm{f}^{-1}\right)^{-1}(\mathrm{~A})=\mathbf{f}(\mathrm{A})$ is an intuitionistic fuzzy supra pre- open set in $\mathrm{Y}$. Hence $\mathbf{f}$ is an intuitionistic fuzzy supra pre-open.

\section{REFERENCES}

[1] M.E. Abd El-Monsef and A.E.Ramadan, “On fuzzy supra topological spaces",Indian J.Pure and Appl, vol. 4, 18(1987), 322-329.

[2] K.T. Atanassov, intuitionstic fuzzy sets, "Fuzzy sets and systems", 209 1986,87-96.

[3] D. Coker, “An introduction to intuitionstic fuzzy topological spaces”, Fuzzy sets and systems, 88(1997), 81-89. 
[4] R. Devi, S. Sampathkumar and M. Caldas, "On supra $\alpha$ - open sets and s $\alpha$ continuous functions General Mathematics", vol. 16, 2 (2008), 77-84

[5] N. Levine, "Semi-open sets and semi-continuity in topological spaces", Amer.Math. Monthly, 70(1963), $36-41$.

[6] M. Parimala, C.Indirani, “Intuitionistic fuzzy $\beta$-supra open sets and Intu- itionistic fuzzy $\beta$-supra continuous mapping”, Notes on intuitionistic fuzzy sets, 20(2014), 6-12.

[7] M. Parimala, Jafari Syaeid, Intuitionistic fuzzy $\alpha$-supra continuous maps,"Annals of fuzzy mathematics and informatics", vol.9, 5(2015), 745-751.

[8] A.S. Mashhour, A. A. Allam, F. S. Mahmoud and F. H. Khedr, "On supra topological spaces", Indian J. Pure and Appl. vol. 4, 14(1983), 502-510.

[9] O.R. Sayed, "Supra pre-open sets and Supra pre-continuity on topological spaces", scientific studies and research series mathematics and informatics, 20(2010), 79 -88.

[10] N. Turnal, “On intuitionistic Fuzzy Supra topological Spaces”, International Conference on Modeling and Simulation, Spain, vol.2, (1999) 69-77.

[11] N. Turnal, “An over view of intuitionstic fuzzy Supra topological spaces”. Hacettepe Journal of Mathematics and Statistics, vol.32 (2003), 17-26.

[12] Won Keun Min, "On fuzzy s- continuous functions", Kangweon - Kyungki, vol.1, 4(1996), 77-82.

[13] Zadeh, L. A. “Fuzzy sets”, Information and Control, 8(1965), 338-353. 